\title{
AUTOMATIC INSPECTION SYSTEM FOR PIPING CORROSION
}

\author{
Yukio Kurosaki \\ Technical Research Institute \\ Research \& Development Division \\ Mitsui Construction Co. . Ltd. \\ 518-1, Komaki, Nagareyama-city \\ Chiba-Pref, 270-01 Japan \\ Phone (+81) 0471-55-4626 Fax (+81)0471-52-9457
}

\section{ABSTRACT}

Pipes used in buildings for supply of hot and cold water, as well as of water for air-conditioning systems, are subject to deterioration due to various facter, which may lead to leakage and blockage of the pipes and to malfunctioning of the systems. Causes of the deterioration vary but one which has shown a rapid increase in recent years is the corrosion of the pipes. A typical example is the phenomenon of "redish water" observed in galvanised steel pipes used for water supply. Reduction of inner diamaters of pipes by and tubercles leads to increased frictional resistance in the pipes and is a factor that may render whole systems unreliable. Under these circumestances, there has been an increasing demand for techniques, not only for arrangement of pipes, but also for diagnosis of deterioration in water pipes in buildings. The present paper provides an outline of an automatic inspection system for piping corrosion, together with examples of diagnosis implemented using the automatic system.

\section{Introduction}

The deterioration of piping for equipment (e.g. pipes for water, hot water, and hot-and-chilled water supply) is caused by a variety of causes, and could cause water leakage and various accidents due to clogging, affecting the operation of equipment adversely. Possible causes of such deterioration are diverse, but corrosion in pipes is becoming a predominant factor in piping deterioration. Besides posing sanitary problems, the deterioration of piping might lead to decreased inside diameters of pipes or clogging due to corrosion products, reducing the reliability of a system of equipment as a whole. Given these adverse effects, it is essential, in maintaining equipment and planning their renewal appropriately, to monitor the deteriorating condition of building equipment accurately. In particular, diagnosis of pipes serving the entire part of a system of building equipment is of vital importance. This paper outlines a newly developed, automatic inspection system for pipes used in building equipment, including its development process, and reports some examples of inspection using the developed system.

\section{Background}

Methods of pipe inspection can largely be classified either as a direct method, which includes the pulling out of pipes from piping systems to inspect their internal surfaces and the use of endoscopes or cameras to check inside, or an indirect method, which includes the estimation of the internal condition of piping systems from water qual i ty.

The direct inspection method guarantees the collection of qualitative and 
quantitative data on deterioration based on results of analyses of corrosion products or scales. This method, however, also had some shortcomings, such as the inevitable shutdown of equipment systems and higher costs of inspection due to pipe extraction work.

On the other hand,

water quality analysis permits estimation of general tendencies, but this method can only provide data which are less reliable and supplementary to the results of inspection by the direct method. The traditional method of measurement using ultrasonic sensors has to be made manually, and requires considerable manpower and time.

It also poses various problems including those concerning the identification of deterioration areas and measuring accuracy.

In view of these problems, the new inspection system was developed with the aim of preventing leakage accidents by grasping the deteriorating condition of the inside of pipes accurately through non-destructive inspection, and determining the appropriate timing for replacement by estimating the remaining service life of piping.

(The configuration of the system is shown in Photo 1.)

\section{Outline of the Inspection Systen}

The inspection system is intended for pipes with inside diameters of $50-150 \mathrm{~mm}$ which are commonly used for equipment piping. This system automatically measures the wall thicknesses (remaining wall thicknesses) of pipes using an ultrasonic probe. The system has the measuring range from $1.5 \mathrm{~mm}$ (min.) to $7.9 \mathrm{~mm}$ (max.) in thickness, which was determined considering the measuring accuracy of the ultrasonic probe. A probe scanner set in a pipe automatically travels on a preset path (which differs depending on inspecting conditions) keeping an appropriate contact between the ultrasonic probe and the pipe surface. The controller/data processor unit controls the traveling and scanning movements of the probe scanner.

It also processes measurement data from an ultrasonic thickness meter in real time and checks measurement data. (Standard specifications of the inspection system are given in Table 1.)

\section{Systen Configuration}

Figs. 1 and 2 gives a view of the probe scanner and illustrate the configuration of the inspection system, respectively. The system consists of a field measuring system and a data analysis system. The field measuring system comprises a probe scanner (ultrasonic probe, traveling-scanning unit), an ultrasonic thickness meter, a controller/data processor unit. A laptop computer controls scanning and data acquisition. The data analysis system analyzes measurement data, and generates graphic representation of deteriorating conditions and outputs reports, as required. Main features of the system's components are as follows.

\section{4- 1 Probe Scanner (Scanner Unit)}

The probe scanner comprises a rotational scanning mechanism and three running mechanisms of clamps. Each of the three runing mechanisms has a set of a servo motor and running wheels. The probe scanner has travelling ranges of $1.0 \mathrm{~m}$ (max.) in the pipe axis direction and 360 degrees around the pipe axis. The scanning speed can be changed within the range from 10 to $60 \mathrm{~mm} / \mathrm{s}$. The travelling range in the pipe axis direction is determined based on the amount of data (depending on scanning pitches) and the capacity of floppy disks used, but the effective travelling range of this system is $1.0 \mathrm{~m}$.

Characteristic beam widths, defect detectability and gain margins were considered 
or stable scanning by the ultrasonic probe, and a broad band transducer (10_ MHz, iameter $6.4 \mathrm{~mm}$ ) was adopted for higher measuring accuracy. Fig. 3 shows results f a dynamic test on artificially eroded models using steel pipes with the inside liameter of $50 \mathrm{~mm}$. (Fig. 4 shows a scanning path of the probe scanner.)

\section{- 2 Controller/Data Processor Unit}

In the field measuring system, scanning conditions (material, diameter and wall hickness of the pipe, scanning pitch, length of the scanning axis, scanning speed, tc.) are input from a laptop computer which has been adopted for reasons of orkability. The field measuring system permits the acquisition of scanning data from he ultrasonic thickness meter and the monitoring of measuring condition.

Fig. 5 gives a flowchart of the measuring process.)

\section{- 3 Data Analysis Systen}

The data analysis system handles the graphic representation of data acquired from ield measurement. This system can display remaining wall thicknesses of the pipe $y$ five shades of gray corresponding to five thickness ranges (based on the wall hickness of the pipe in its initial state; every 20\%). It also can display the ondition of deterioration including the most eroded areas (with the minimum wall hickness) in the cross section and the longitudinal section of the pipe. As an ption, the system has a numerical analysis function, called statistical analysis unction, which permits the calculation and display of the area ratios by different hades of gray representing remaining wall thicknesses of the pipe, and the number of ion-acoustical contacts of the ultrasonic sensor by which the reliability of data btained can be checked.

\section{Exanples of Pipe Inspection}

After its functional test, the inspection system was field-tested and brought nto use in July 1989. This section reports actual inspections of a 20-year-old uilding ( $N$ building) and a 24-year-old building ( $S$ building).

(Photo 2 shows the setup of the probe scanner ( $\mathrm{N}$ building).)

\section{Preparation for Inspection and Establishment of Scanning Conditions}

In preparation for inspection, heat insulating materials were removed and couplant ras applied. Then, the probe scanner was set up and measurement was performed. In his scanning, the traveling speed in the pipe axis direction was set to $5 \mathrm{~mm} / \mathrm{s}$, the circumferential scanning speed to $30 \mathrm{~mm} / \mathrm{s}$, the scanning pitch to $2.0 \mathrm{~mm}$, and the scanning range in the pipe axis direction to $450 \mathrm{~mm}$. Measurements were taken from 31 . 00 grid squares (2 mm $\times 2 \mathrm{~mm}$ grid squares).

\section{- 2 Overviev of the Results of Measurement}

Table 2 summarizes measured remaining wall thicknesses of pipes (N building). xamples of outputs for measurements of water pipes ( $N$ building) and chilled water ipes ( $S$ building) with different deterioration patterns (corrosion patterns) are given in Figs. 6, 7 and 8. Results of inspection in $\mathrm{N}$ building shows that the remaining wall hicknesses of both hot-water and cooling pipes are $2.0 \mathrm{~mm}$ or more.

It is thought, 
from the lengths of periods during which these pipes have been used, that they are unlikely to pose any problems in the near future. However, remaining thicknesses of $0.84 \mathrm{~mm}$ or more and less than $1.68 \mathrm{~mm}$ were observed in 15 grid squares, indicating higher levels of local deterioration than in other pipes. This is because of the difference in corrosion patterns, and it is thought that there will be no problems for the moment, though some care needs to be taken. Results of inspection in $S$ building show different patterns of corrosion in different parts of pipes of the same type (chilled-water pipes).

Fig. 7 shows a pattern of evenly distributed, considerable corrosion on the exit side of a cooling tower. The minimum remaining wall thickness is $1.6 \mathrm{~mm}$, indicating the need for some quick measures. Fig. 8 shows deterioration on the exit side of a pump. This figure shows a mixture of a groove-like distribution of corrosion at the electro-resistance-welded joint and a localized distribution of corrosion nearby. The minimum remaining thickness is $2.1 \mathrm{~mm}$, which also requires some kind of measures, as with the pipe on the exit side of the cooling tower.

In deterioration diagnosis, corrosion patterns are classified based on such data, and an average corrosion ratio and an estimated remaining service life are calculated. Then, comprehensive judgments are made as to whether there is a need for some measures (replacement or repair), taking account of piping material characteristics, intended uses, results of water examination, and past accidents, in addition to data obtained by the inspection system. The above measuring procedure including preparation for it takes about 90 minutes per grid square (total measuring time 70 min., measuring time per grid square 7.3 sec.). It is thought that this inspection system is practicable enough in terms of measuring accuracy achievable and the time required for measurement.

\section{Concluding Remarks}

This inspection system has already been put to practical use and has proved to be an effective non-destructive inspection tool, as intended, for pipe deterioration caused by ordinary corrosion. In its applications to date, this system has been positioned as one of the methods for comprehensive diagnosis and has been combined with other methods, as required. At present, however, it is also true that judgments by experienced persons is an important factor in the final judgment based on the corrosion patterns and estimated remaining service lives of pipes in question.

To enhance the reliability of the system, the authors plan improvements of both hardware, such as a hold/feed mechanism of the probe to suit the surface condition of pipes, and software, such as a method of estimating the remaining service lives of pipes, whose problems were recognized through actual use. It is the authors' earnest hope that this system will help to improve the techniques of building equipment inspect ion.

\section{References}

(1) Yukio Sato and Kazuyoshi Matsuoka:"Study of Estimation on Remaining Life of Metallic material for Structure, "Journal of NDI (Japan), Vo1. 33, No. 6, P. 453

(2) The Japanease Society for Non-Destructive Inspection: "The Method of Defect Detectability by Ultrasonic" (B), P.17, (1987) 


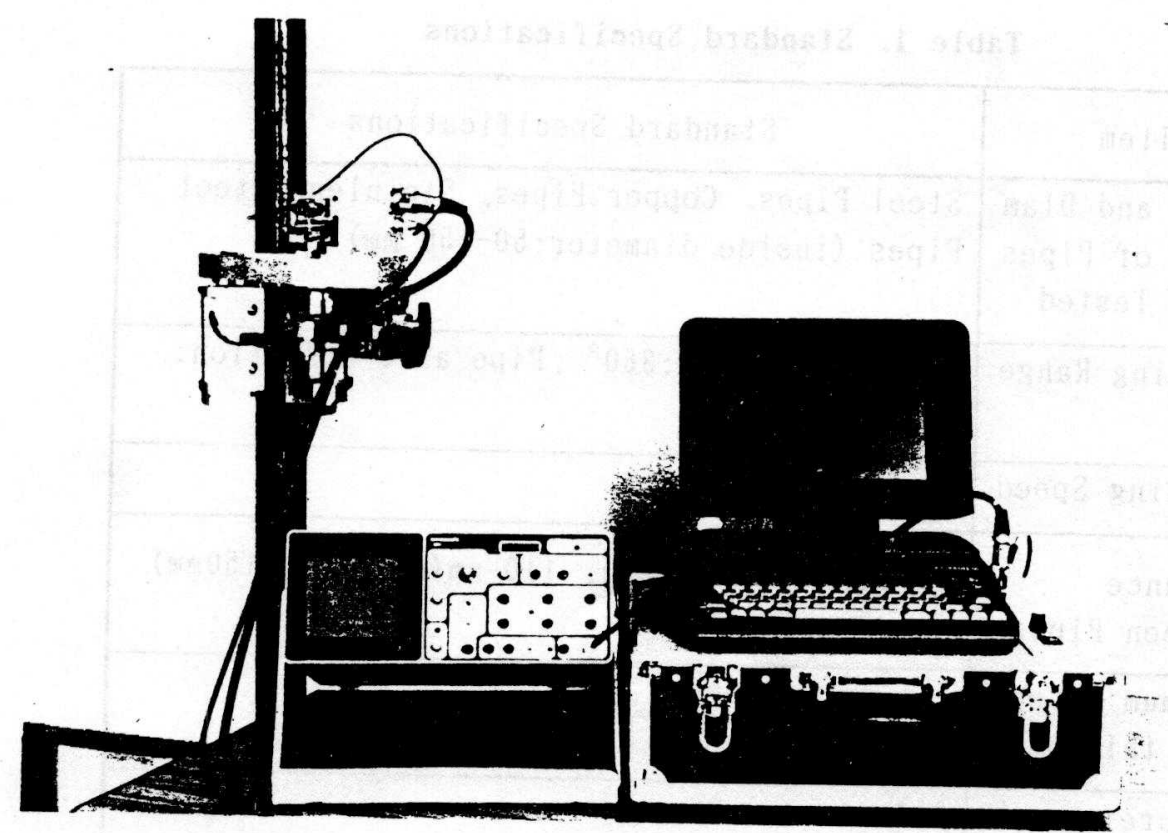

Photo 1. Configuration of Pipe Inspection System

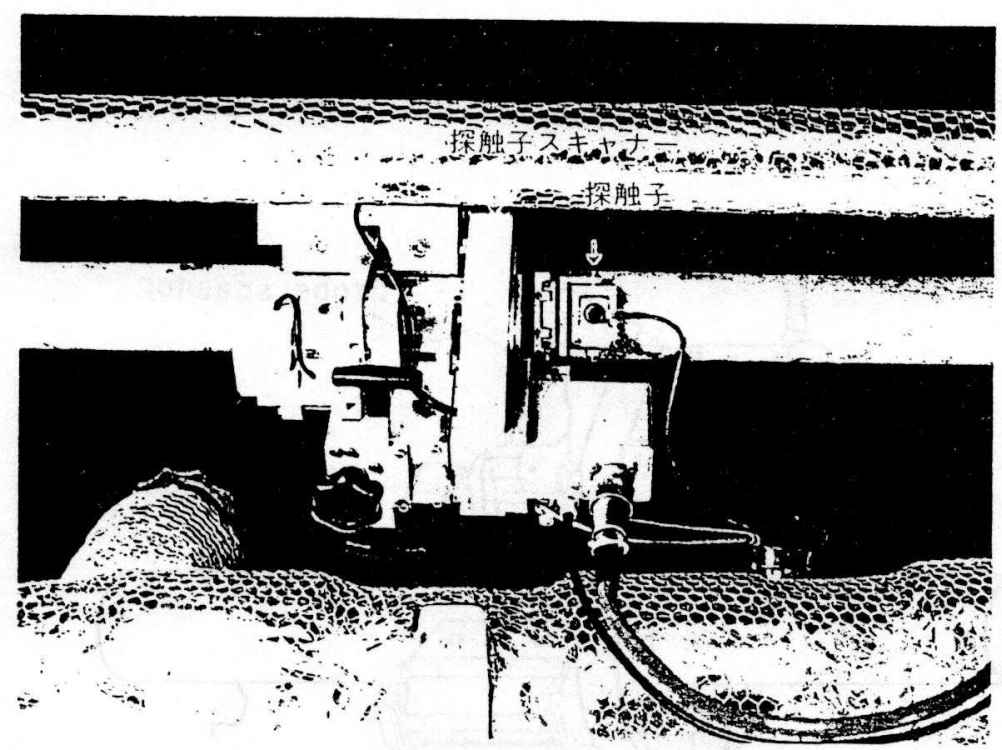

Photo 2. Setup of Probe Scanner 
Table 1. Standard Specifications

\begin{tabular}{|c|c|}
\hline I tem & Standard Specifications \\
\hline $\begin{array}{l}\text { Types and Diam } \\
\text { eters of Pipes } \\
\text { to be Tested }\end{array}$ & $\begin{array}{l}\text { Steel Pipes, Copper Pipes, Stainless steel } \\
\text { Pipes (inside diameter:50-150 mm) }\end{array}$ \\
\hline Scanning Range & $\begin{array}{l}\text { Circumferential: } 360^{\circ} \text {, Pipe axis direction: } \\
1.0(\max )\end{array}$ \\
\hline Scanning Speed & $10-60 \mathrm{~mm} / \mathrm{sec}$ \\
\hline $\begin{array}{l}\text { Distance } \\
\text { between Pipes }\end{array}$ & $75 \mathrm{~mm}$ (bore: $50-80 \mathrm{~mm}), 110 \mathrm{~mm}$ (bore: $90 \sim 150 \mathrm{~mm})$ \\
\hline $\begin{array}{l}\text { Minimum detect } \\
\text { able thickness }\end{array}$ & $1.5 \mathrm{~mm}$ or more \\
\hline $\begin{array}{l}\text { Measureing } \\
\text { Accuracy }\end{array}$ & $0.1 \mathrm{~mm}$ \\
\hline $\begin{array}{l}\text { Image Processi } \\
\text { ng Software }\end{array}$ & Piping development \\
\hline Weight & $7 \mathrm{~kg}(280 \mathrm{H} \times 230 \mathrm{~W} \times 260 \mathrm{~L})$ for $50-80 \mathrm{~mm}$ pipes \\
\hline
\end{tabular}

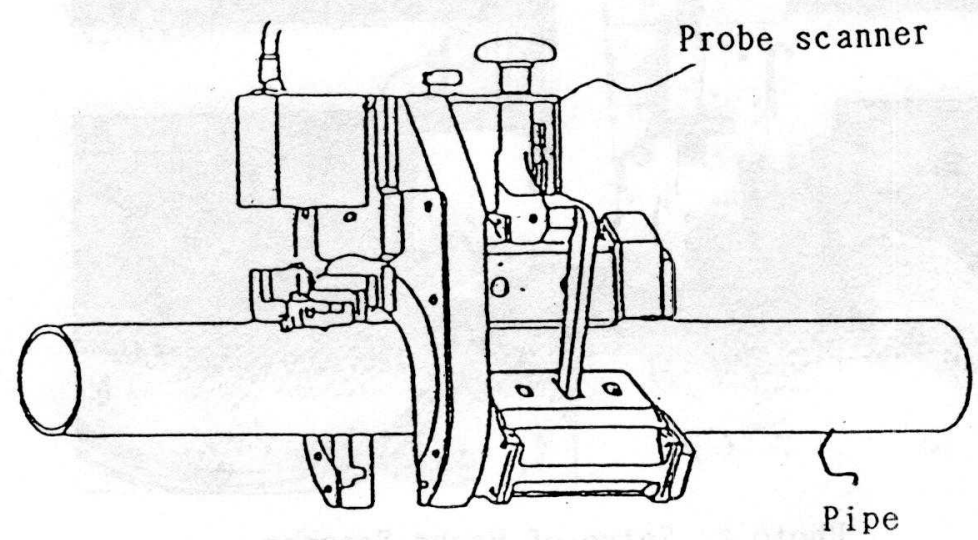

Fig. 1. Probe Scanner 


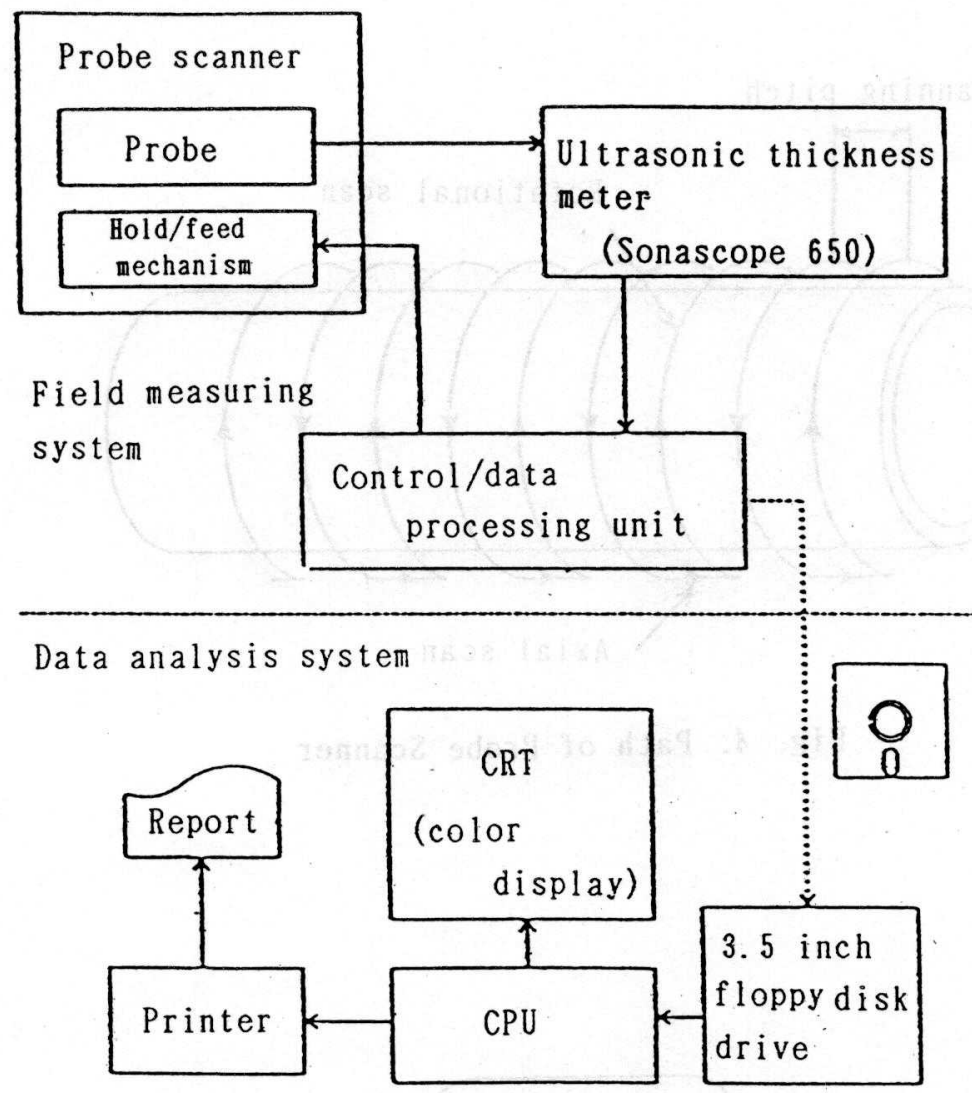

Fig. 2. Systen Configuration

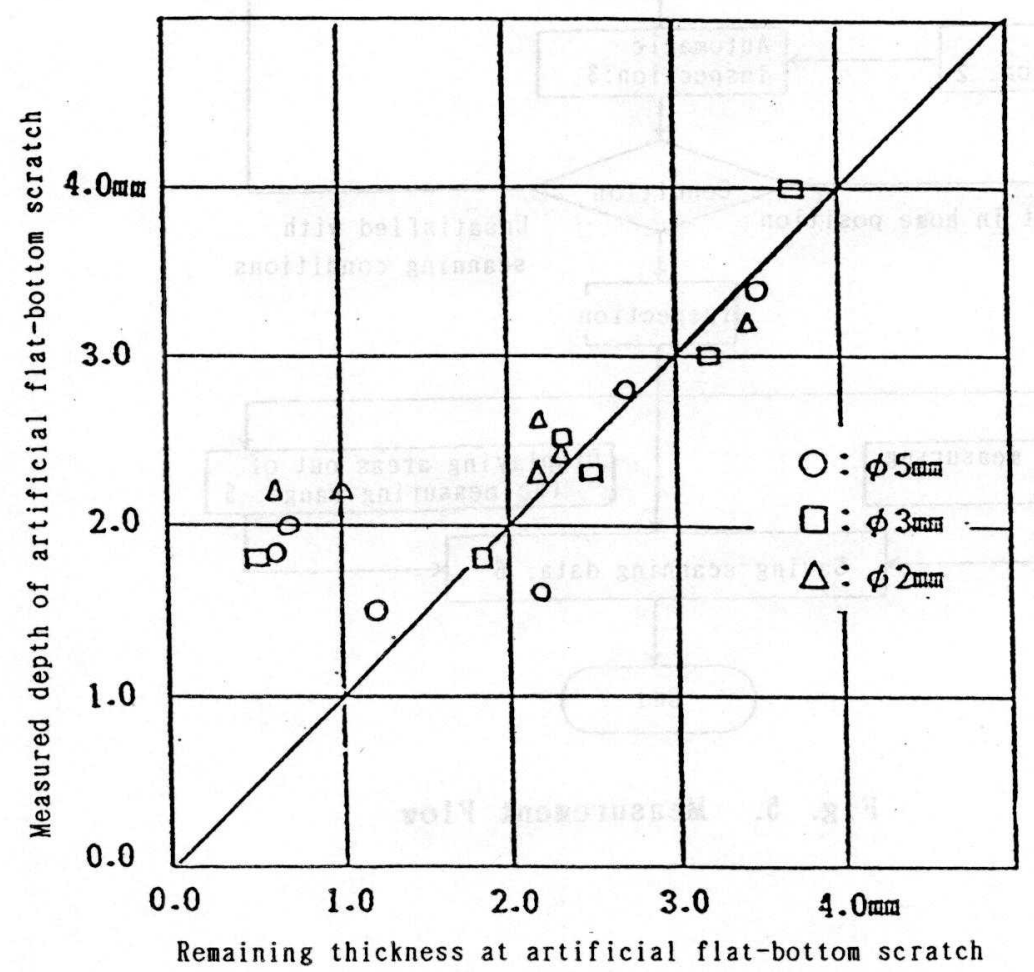

Fig. 3. Result of Dynamic Test Using Artificially Eroded Models 


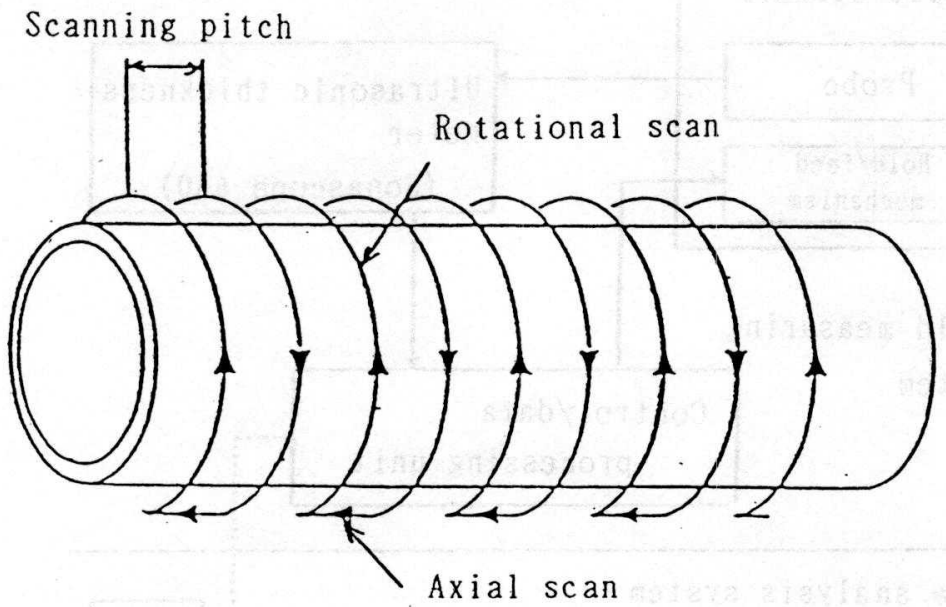

Fig. 4. Path of Probe Scanner

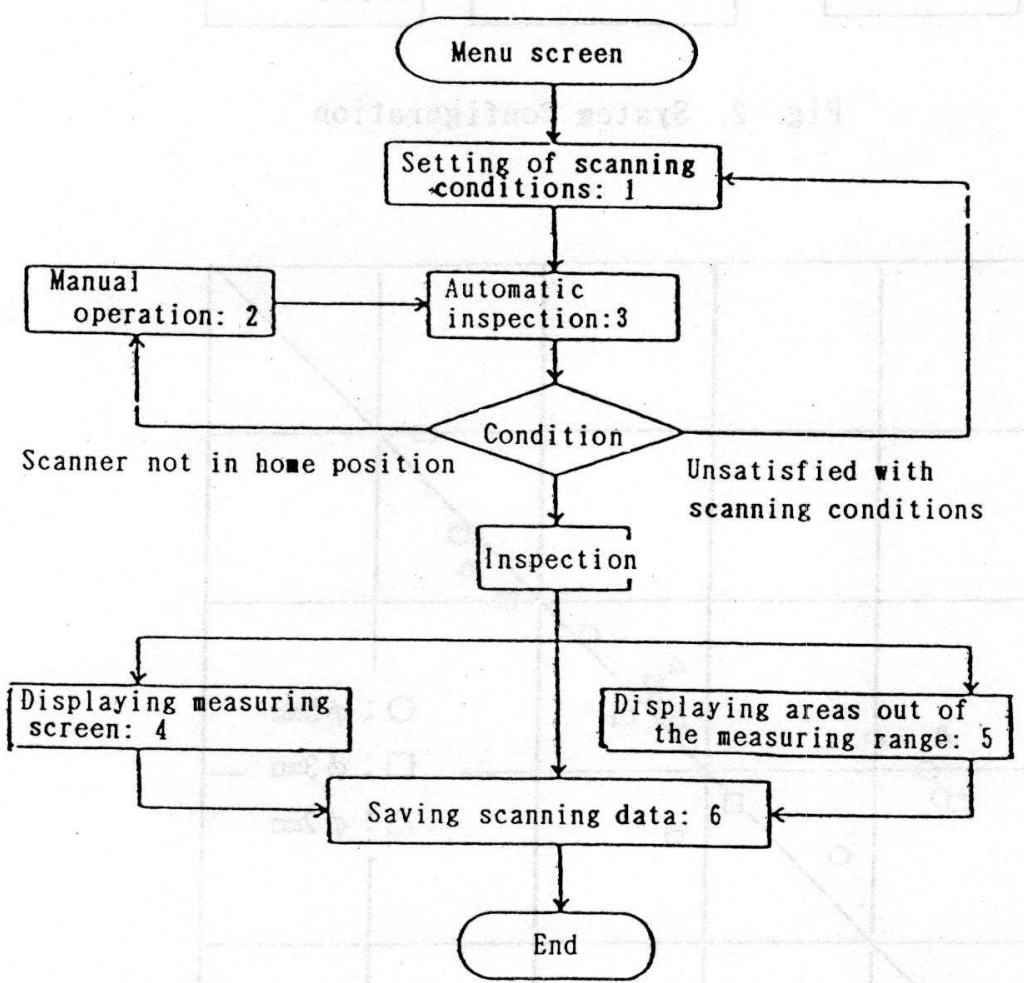

Fig. 5. Measurement Flov 
Table 2. Remaining Thickness(N Building)

\begin{tabular}{|c|c|c|c|c|c|c|}
\hline \multirow{2}{*}{ Pipe } & \multicolumn{5}{|c|}{ Remaining Thlckness (min) } & \multirow{2}{*}{$\begin{array}{l}\text { Number of non- } \\
\text { acoust ical } \\
\text { contacts }\end{array}$} \\
\hline & $\begin{array}{l}\text { Less than } 20 \% \\
\text { (Less than } 0.81 \mathrm{~mm} \text { ) }\end{array}$ & $\begin{array}{l}20 \% \text { or more and } \\
\text { less than } 10 \% \\
(0.81 \text { or more } \\
\text { and less than } \\
1.68 \mathrm{ma})\end{array}$ & $\begin{array}{l}10 \% \text { or wore and } \\
\text { less than } 60 \% \\
\text { (1.68 or more } \\
\text { and less than } \\
2.62 \text { (n) }\end{array}$ & $\begin{array}{l}60 \% \text { or wore and } \\
1058 \text { than } 80 \% \\
(2.62 \text { or wore } \\
\text { and les8 than } \\
3.38 \text { ma) }\end{array}$ & $\begin{array}{l}80 \% \text { or more } \\
(3.36 \text { or } \operatorname{mor} \theta)\end{array}$ & \\
\hline $\begin{array}{l}1 \text { Hot vater } \\
\text { Dipe }\end{array}$ & $0(0)$ & $0(0)$ & $0.1(133)$ & $2.2(696)$ & $97.2(90631)$ & 10 \\
\hline 2 Macer pipe & $0(0)$ & $0.01(15)$ & $3.7(1180)$ & $19.7(1330)$ & $82.1(25868)$ & 107 \\
\hline 3 Cooling Dide & $0(0)$ & $0(0)$ & $2.3(615)$ & $17.7(1597)$ & $79.8(20683)$ & 5 \\
\hline
\end{tabular}

Note: 1. Figures in parentheses show the number of non-acoustical contacts based on a $2 \mathrm{~mm} \times 2 \mathrm{~mm}$ (circumferential direction $x$ axial direction) grid square system.

2. Figures in the above table are remaining thickness area ratios.

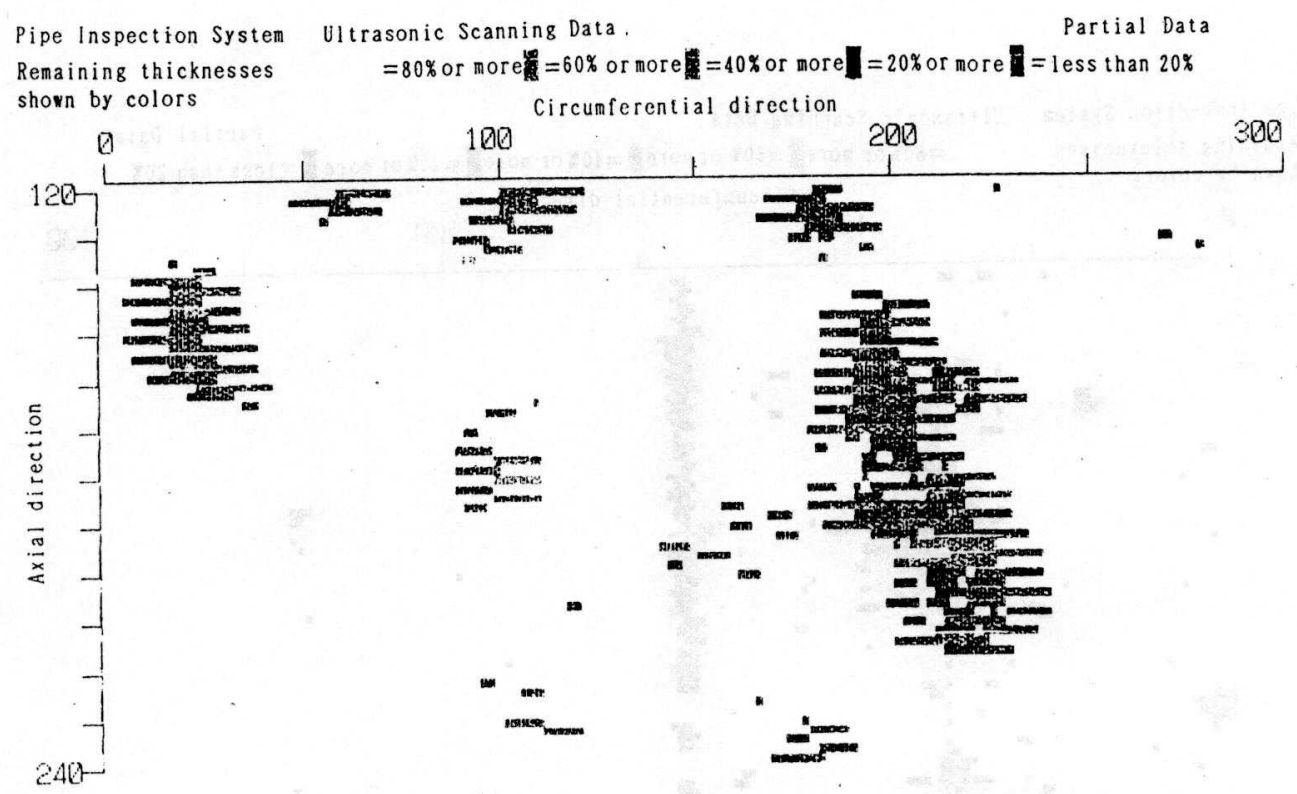

Fig. 6. Result of Measurement of A Tater Pipe (N Building) 


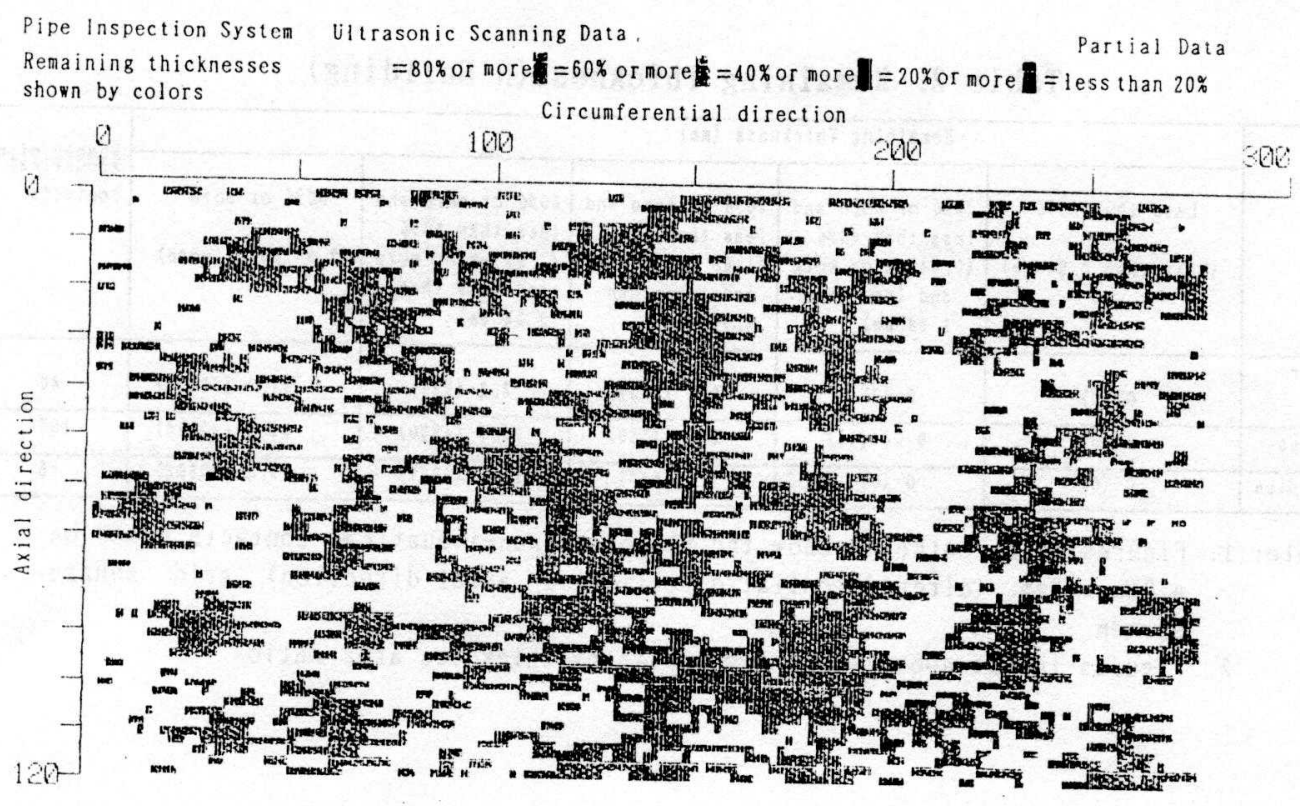

Fig. 7. Result of Measurement of Chilled-Tater Pipe A (S Building)

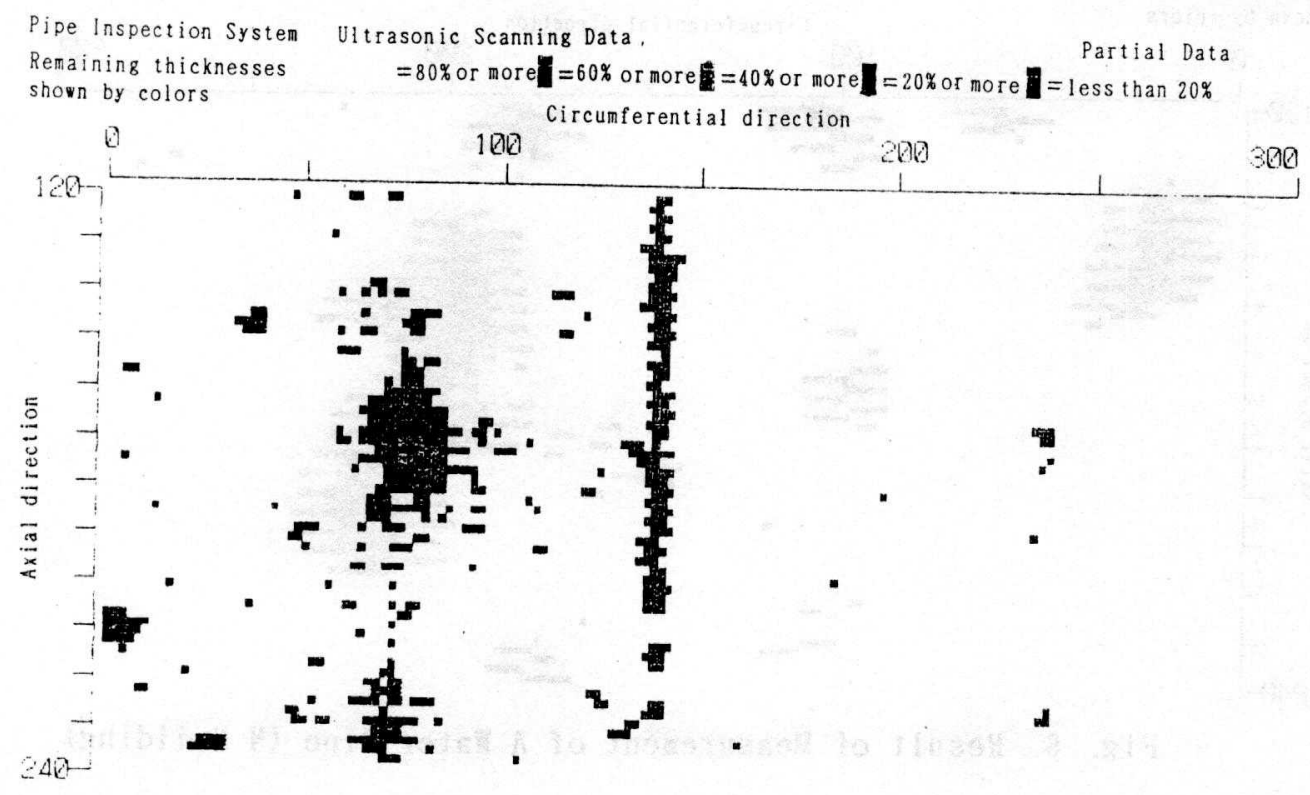

Fig. 8. Result of Measurement of Chilled-later Pipe B (S Building) 